\title{
Study on Removal of Urethral Catheter Immediately versus after 12 Hours following Caesarean Section - A Prospective Randomized Controlled Trial
}

\author{
Shyamal Dasgupta ${ }^{1}$, Chiranjit Ghosh ${ }^{2}$, Jhuma Biswas ${ }^{3}$, Archi Ghanti' ${ }^{4}$, Kashmira Majumder ${ }^{5}$
}

${ }^{1}$ Associate Professor, Department of Obstetrics and Gynaecology, R. G. KAR Medical College \& Hospital, Kolkata, West Bengal, India. ${ }^{2}$ RMO-CUM-Clinical Tutor, Department of Obstetrics and Gynaecology, R. G. KAR Medical College \& Hospital, Kolkata, West Bengal, India. ${ }^{3}$ Associate Professor, Department of Obstetrics and Gynaecology, R. G. KAR Medical College \& Hospital, Kolkata, West Bengal, India. ${ }^{4}{ }^{\text {nd }}$ Year Postgraduate Trainee, Department of Obstetrics and Gynaecology, R. G. KAR Medical College \& Hospital, Kolkata, West Bengal, India. ${ }^{5}$ Ex-Postgraduate Trainee,

Department of Obstetrics and Gynaecology, R. G. KAR Medical College \& Hospital, Kolkata, West Bengal, India.

\section{ABSTRACT}

\section{BACKGROUND}

The most common obstetric surgical procedure is Caesarean section and it is associated with urinary tract infection which is related to prolonged use of indwelling catheter post-operatively. It is also associated with late ambulation and its complications. A five-year audit from a large teaching hospital in Kolkata showed a caesarean section rate of 49.9 percent amongst all deliveries and another study in Madras showed Caesarean section rate of 50 percent. Caesarean section like any other surgical procedure is not without risks.

\section{METHODS}

A prospective randomized control trial was done at R.G. Kar Medical College with 436 patients, equally distributed in two arms. In one arm, catheter was removed after twelve hours (control) and in the other arm (study group), the catheter was removed immediately after Caesarean section.

\section{RESULTS}

In the present study, amongst the result parameters, significant bacteriuria [Group A- 3 (1.4\%) and Group B- 50 patients (22.9\%)]; dysuria [Group A- 5 (2.3\%) patients and Group B- 47 (21.6\%)]; urinary frequency and urgency [Group A- $2(0.9 \%)$ and Group B- $44(20.2 \%)]$ were statistically significant $(p<0.00001)$. On the other hand, association of fever [Group A-5 (2.3\%) and Group B- 9 patients (4.1\%)] and retention of urine after catheter removal [Group A- 4 (1.8\%) and Group B- 5 $(2.3 \%)]$ did not show statistically significant difference between the two groups ( $>0.00001)$. But, duration of hospital stay in days (Chi-square value-89.8014) and post-operative ambulation time in hours (Chi-square value-287.3246), both show statistically significant difference between the two groups. $(\mathrm{p}<0.00001)$.

\section{CONCLUSIONS}

Immediate removal of the catheter post-operatively is definitely associated with decreased incidence of urinary symptoms and problems related to late ambulation. It is hoped that the results of the study will be clinically useful, and it will be beneficial in formulating a strategy for removal of catheter after Caesarean section. However, to formulate a globally accepted protocol regarding time of catheter removal, studies with larger sample size and preferably multi-centric studies are necessary.

\section{KEY WORDS}

Caesarean Section, Catheterization, Urinary Tract Infection, Ambulation
Corresponding Author: Dr. Chiranjit Ghosh, \#143/1C, South Sinthee Road, Kolkata-700050, West Bengal, India. E-mail: chiranjit1980@gmail.com

DOI: $10.14260 / j e m d s / 2019 / 651$

Financial or Other Competing Interests: None.

How to Cite This Article:

Dasgupta S, Ghosh C, Biswas J, et al. Study on removal of urethral catheter immediately versus after 12 hours following caesarean section- a prospective randomized controlled trial. J. Evolution Med. Dent. Sci. 2019;8(40):2996-3000, DOI: $10.14260 / \mathrm{jemds} / 2019 / 651$

Submission 11-08-2019,

Peer Review 15-09-2019,

Acceptance 25-09-2019,

Published 07-10-2019. 


\section{BACKGROUND}

The most common obstetric surgical procedure performed worldwide is Caesarean section which may be emergency or elective. A five-year audit from a large teaching hospital in Kolkata showed a caesarean section rate of 49.9 percent amongst all deliveries, ${ }^{1}$ and another study in Madras showed Caesarean section rate of 50 percent. ${ }^{2}$ Caesarean section like any other surgical procedure is not without risks. It carries all the complications associated with any major surgery, including major organ injury. ${ }^{3}$

Urinary catheterization is routinely performed empirically during caesarean section, giving benefits including bladder decompression leading to proper visualization of lower uterine segment, lower chances of bladder injury ${ }^{4}$ and minimizing urinary retention in the postoperative period.5,6 But, the duration of catheter use in the post-operative period is highly variable, ranging from immediately after the operation up to twelve hours later or even more. It is custom based and is mostly personal preference dependent. Every hospital has its own policy regarding this issue. In our hospital, it is widely variable amongst different units as no specific protocol has been established. However, most of the units follow the guideline of keeping the catheter for 12-24 hours after caesarean section. First void time should occur within 6 hours after removal of the catheter, and ambulation of the patient should occur within 24 hours post-procedure. However, indwelling catheters cause significant discomfort to the patients like uneasiness, delayed ambulation and increased risk of Urinary Tract Infection (UTI). ${ }^{7}$ The introduction of an indwelling catheter into the urinary bladder bypasses the body's normal defense mechanisms and enables micro-organisms to enter the urinary bladder. Once a catheter is in place, bacteria in the urinary drainage bag, or introduced via the catheter create a film like structure known as biofilm on the surface of the catheter lumen which is a precursor to Urinary Tract Infection. Catheter related UTIs are one of the most common healthcare associated infection reported to the National Healthcare Safety Network (NHSN), a tracking system for health care associated infections that provides organizations with data to identify problem areas and measures progress of prevention efforts (CDC, 2014). Therefore, immediate postoperative removal of the catheter may lead to early ambulation and protection from developing thromboembolic manifestations and many urinary symptoms including UTI.

All these issues have been addressed in a few clinical trials. The present study is designed to compare the results of immediate versus twelve-hour postoperative removal of urinary catheter after Caesarean section and to determine whether early removal can be beneficial in allowing early ambulation and reducing risks of UTI.

We wanted to compare the effects of demographic variables (age, body mass index (BMI), gestational age in weeks) and categorical variables (previous caesarean section, fever, urinary retention needing re-catheterization, significant bacteriuria, dysuria, urinary frequency/ urgency) on immediate versus 12-hour post-operative removal of urinary catheter after caesarean section and determine as to whether early removal can be beneficial with regard to early ambulation and reduction of risk of urinary symptoms including UTI.

\section{METHODS}

A prospective randomized control trial was done between July 2016 to June 2017 in the Department of Obstetrics and Gynaecology, R.G. Kar Medical College and Hospital, Kolkata. Patients admitted in the Antenatal ward, undergoing elective or emergency $\mathrm{C}$-section were studied. All the patients were subjected to thorough history taking and clinical examination. Basic routine investigations were performed in all these patients to rule out co-morbidities. Patients with UTI, significant vaginal bleeding, prolonged labour, severe preeclampsia and eclampsia, Gestational Diabetes Mellitus, overt diabetes or renal pathology or having any condition requiring postoperative monitoring of urinary output were excluded from our study. Randomization was done using a computergenerated randomization list drawn up by a statistician. The study was done after getting ethical clearance from the institution and with proper written informed consent from the subjects in standard proforma.

A relatively recent prospective clinical trial was performed by El Mazny A, El Sharkawy M, Hassan A at a university teaching hospital in Cairo, Egypt from November 2012 to March 2014.8 300 eligible women admitted for primary or repeat Caesarean section were taken in the study. They were allocated into two groups in a 1:1 ratio by block randomization using computer generated random numbers. In all the participants, a Foley's urethral catheter (French size 16) was inserted under sterile condition on the operation table immediately before caesarean section. Caesarean was performed using standard steps. In this study by El Mazny et al., it was found that the incidence of significant bacteriuria in postoperative patient of caesarean section when catheter was removed immediately after surgery and when catheter removed after twelve hours was $9.3 \%$ and $19.3 \%$ respectively. Keeping an alpha error of 0.05 and beta error of $0.2(80 \%$ power) a sample size of 422 was taken. Considering an attrition rate of $3 \%$, a total no. of 436 patients were taken in our study, 218 in each arm.

In our study, Caesarean section was performed in all patients assigned to the study in a standard manner under spinal or general anaesthesia. Before the surgical procedure, a Foley's Catheter of appropriate size was inserted in all patients in the operation theatre, taking all aseptic precautions. In the study group(designated as Group A), the Foley's catheter was removed immediately after the operation before sending to ward while in the other group(designated as Group B), the catheter was removed after twelve hours in the ward. All the patients received same regimen of intravenous fluids, antibiotic prophylaxis and post-operative analgesia.

After removal of catheter, patients were encouraged to void urine spontaneously. In case if the patients had difficulty in voiding urine or had no urge to void after six hours and/or abdominal examination showed palpable urinary bladder, recatheterization was done aseptically. Midstream sample of urine was collected in all patients 24 hours postoperatively and sent for culture. Urine culture was repeated if patients had urinary symptoms like dysuria, urgency, frequency, with or without fever more than 38.5 degree centigrade at any time during hospital stay. 


\section{Statistical Analysis}

Numerical variables were evaluated using unpaired Student's t-test. Categorical variables were analysed by Chi-square test. GraphPad Prism Version 4, Santiago California, GraphPad Software inc. 2005 were used for data analysis. A Two-tailed p-value of $<0.05$ was considered statistically significant.

\section{RESULTS}

In the present study, the differences in mean age [p value $=0.8759]$, BMI $[p=0.0629]$, gestational weeks $[p=0.959]$, incidence of previous Caesarean section $[\mathrm{p}=0.81582]$ were tabulated (Table $1 \& 3$ ) and shows no statistically significant difference between Group A and Group B subjects.

In the Table 3, significant bacteriuria [Group A-3(1.4\%) and Group B-50 patients (22.9\%)]; dysuria [Group A$5(2.3 \%)$ patients and Group B-47(21.6\%)]; urinary frequency and urgency [Group A-2(0.9\%) and Group B 44-(20.2\%)] have been tabulated. All were statistically significant $(\mathrm{p}<0.00001)$.

On the other hand, association of fever and retention of urine after catheter removal did not show statistically significant difference between the two groups. But, duration of hospital stay in days and post-operative ambulation time in hours, both show statistically significant difference between the two groups. $(\mathrm{p}<0.00001)$.

\begin{tabular}{|c|c|c|c|c|}
\hline Demographic Parameters & Groups & Mean & SD & p Value \\
\hline \multirow[b]{2}{*}{ Age(Years) } & Group A & 25.8303 & 3.9970 & \multirow[b]{2}{*}{0.8759} \\
\hline & Group B & 25.7706 & 3.9714 & \\
\hline \multirow{2}{*}{ Gestational Weeks } & Group A & 37.6468 & 1.9126 & \multirow{2}{*}{0.959} \\
\hline & Group B & 37.6560 & 1.8998 & \\
\hline \multirow{2}{*}{$\operatorname{BMI}\left(\mathrm{kg} / \mathrm{m}^{2}\right)$} & Group A & 21.6138 & 1.6599 & \multirow{2}{*}{0.0629} \\
\hline & Group B & 21.9087 & 1.6430 & \\
\hline $\begin{array}{r}\text { Table 1. Distribution } \\
\text { the Study Gr }\end{array}$ & lom & Paran & $\begin{array}{l}\text { rs bet } \\
p \text { B }\end{array}$ & \\
\hline
\end{tabular}

\begin{tabular}{|c|c|c|c|c|c|}
\hline \multicolumn{3}{|c|}{ Hospital Stay } & \multicolumn{2}{c|}{ Post-Operative Ambulation } \\
\hline In Days & $\begin{array}{c}\text { No. of Patients } \\
\text { (Percentage of Total) }\end{array}$ & In Hours & $\begin{array}{c}\text { No. of Patients } \\
\text { (Percentage of Total) }\end{array}$ \\
\hline & Group A & Group B & & Group A & Group B \\
\hline 5 & $212(97.2 \%)$ & $132(60.6 \%)$ & 4 & $172(78.9 \%)$ & $0(0 \%)$ \\
\hline 6 & $3(1.4 \%)$ & $31(14.2 \%)$ & 8 & $22(10.1 \%)$ & $74(33.9 \%)$ \\
\hline 7 & $1(0.5 \%)$ & $28(12.8 \%)$ & 12 & $18(8.3 \%)$ & $96(44 \%)$ \\
\hline 8 & $0(0 \%)$ & $14(6.4 \%)$ & 18 & $6(2.8 \%)$ & $32(14.7 \%)$ \\
\hline 10 & $2(0.9 \%)$ & $6(2.8 \%)$ & 20 & $0(0 \%)$ & $14(6.4 \%)$ \\
\hline $12 \&$ above & $0(0 \%)$ & $7(3.2 \%)$ & 24 & $0(0 \%)$ & $2(0.9 \%)$ \\
\hline $\begin{array}{c}\text { Chi-square } \\
\text { value }\end{array}$ & 89.8014 & $\begin{array}{c}\text { Chi-square } \\
\text { value }\end{array}$ & 287.3246 \\
\hline p-value & \multicolumn{3}{|c|}{$<0.00001$} & p-value & $<0.00001$ \\
\hline \multicolumn{6}{|c|}{ Table 2. Distribution of Hospital Stay and Post-Operative } \\
Ambulation Time in the Two Groups \\
\hline
\end{tabular}

\begin{tabular}{|c|c|c|c|c|c|c|}
\hline $\begin{array}{c}\text { Sl. } \\
\text { No. }\end{array}$ & Parameters & Group & $\begin{array}{l}\text { No. }(\% \text { of } \\
\text { Total } \\
\text { Cases) }\end{array}$ & $\begin{array}{c}\text { Yes }(\% \text { of } \\
\text { Total Cases) }\end{array}$ & \begin{tabular}{|c|} 
Chi- \\
Square \\
Value
\end{tabular} & p-Value \\
\hline \multirow[b]{2}{*}{1.} & \multirow{2}{*}{$\begin{array}{l}\text { Previous } \\
\text { Caesarean } \\
\text { section }\end{array}$} & $\mathrm{A}$ & $170(78 \%)$ & $48(22.0 \%)$ & \multirow[b]{2}{*}{0.0542} & \multirow[b]{2}{*}{0.81582} \\
\hline & & B & $172(78.9 \%)$ & $46(21.1 \%)$ & & \\
\hline \multirow{2}{*}{2.} & \multirow{2}{*}{ Fever } & $\mathrm{A}$ & $213(97.7 \%)$ & $5(2.3 \%)$ & \multirow{2}{*}{1.1808} & \multirow{2}{*}{0.27719} \\
\hline & & B & $209(95.9 \%)$ & $9(4.1 \%)$ & & \\
\hline \multirow[b]{2}{*}{3.} & \multirow{2}{*}{$\begin{array}{c}\text { Urinary retention } \\
\text { needing re- } \\
\text { catheterization } \\
\end{array}$} & $\mathrm{A}$ & $214(98.2 \%)$ & $4(1.8 \%)$ & \multirow[b]{2}{*}{0.1135} & \multirow[b]{2}{*}{0.7362} \\
\hline & & B & $213(97.7 \%)$ & $5(2.3 \%)$ & & \\
\hline \multirow{2}{*}{4.} & \multirow{2}{*}{$\begin{array}{c}\text { Significant } \\
\text { bacteriuria }\end{array}$} & A & $215(98.6 \%)$ & & \multirow{2}{*}{47.4469} & \multirow{2}{*}{$<0.00001$} \\
\hline & & B & $168(77.1 \%)$ & $50(2$ & & \\
\hline \multirow{2}{*}{5.} & \multirow{2}{*}{ Dysuria } & $\mathrm{A}$ & $213(97.7 \%)$ & $5(2.3 \%)$ & \multirow{2}{*}{38.5168} & \multirow{2}{*}{$<0.00001$} \\
\hline & & $\mathrm{B}$ & $171(78.4 \%)$ & $47(21.6 \%)$ & & \\
\hline \multirow[b]{2}{*}{6.} & \multirow{2}{*}{$\begin{array}{l}\text { Urinary } \\
\text { frequency/ } \\
\text { urgency }\end{array}$} & $\mathrm{A}$ & $216(99.1 \%)$ & $2(0.9 \%)$ & \multirow[b]{2}{*}{42.8709} & \multirow[b]{2}{*}{$<0.00001$} \\
\hline & & B & $174(79.8 \%)$ & $44(20.2 \%)$ & & \\
\hline & & , & & & & \\
\hline
\end{tabular}

\section{DISCUSSION}

Worldwide there is an upward trend in the number of caesarean sections, performed either on emergency or elective basis. The reported regional rates of caesarean section are $3.3 \%$ in Africa, 33.7\% in Latin America, 27.3\% in Asia, $40.5 \%$ in China and overall global average of Caesarean section is $15.9 \% .{ }^{9}$ In India, the rate of caesarean section delivery has increased from $3 \%$ to $10 \%$ between $1992-93$ and 2005-06 (IIPS, 2007). Considering the huge population of India, an astronomical number of caesarean sections are performed in various institutions of India every year.

Each surgery whether major or minor requires a certain set of pre-operative preparation. Caesarean section is no exception. One of such pre-operative preparation during Caesarean section is the routine placement of indwelling urinary catheter prior to operative procedure. The rationale for routine catheterization is to prevent bladder injury and minimize intra-operative difficulties in the belief that an empty bladder is at less risk of damage than the one that is distended. It also reduces post-operative urinary retention and facilitates proper measurement of urine output which may be helpful in certain situations. Urinary catheterization during caesarean section is an age-old practice but not a harmless one. Indwelling catheters are associated with an increased risk of infection in the urinary tract 7 . It may lead to Catheter Associated Asymptomatic Bacteriuria (CA-ASB), where the patient is asymptomatic or Catheter Associated Urinary Tract Infection (CA-UTI), where the patient is having frank symptoms like fever, chills, dysuria, increased urinary frequency etc. The accepted threshold for bacteriuria to meet definition of CA-UTI is $10^{3}$ or more Colony Forming Units $(\mathrm{CFU}) / \mathrm{ml}$ in midstream clean catch urine sample, whereas to meet the threshold for CA-ASB is $10^{5}$ or more CFU $/ \mathrm{ml}$. CAASB may also lead to CA-UTI later. Catheter related UTI may be attributed to bacteria introduced via the catheter or indwelling bacterial flora creating a biofilm on the catheter lumen predisposing to UTI. Also, prolonged catheterization may lead to significant discomfort to the patient and also delays ambulation time which may predispose to some thromboembolic complications like Deep Venous Thrombosis, thrombophlebitis etc. although these are rare in our country. Moreover, inadvertent traction on the catheter may traumatize the bladder neck, leading to episodes of hematuria. Accidental intra-urethral distension of the Foley's catheter balloon may lead to pressure necrosis and urethral rupture. These may lead to significantly increased morbidity in the post-operative period, increasing the duration of hospital stay. In a developing country like India where the delivery rate is very high and caesarean section comprises up to 50 percent in some tertiary referral centres, early removal of catheter may reduce many complications including hospital overstay which in turn reduces the health care burden considerably.

In the Study conducted by El Mazny et al ${ }^{8}$ in one group, catheter was removed immediately after the procedure; whereas in the second group, catheter was removed 12 hours post-operatively. Patients in Group A were asked to void upon feeling the urge. If the urge was felt at a time when mobilization was impossible, a bedpan was given. If the desire to void was reported later, they were helped to a 
nearby bathroom. If the patient still had difficulty in passing urine after 6 hours and/or abdominal examination showed palpable urinary bladder, re-catheterization was done. The main outcome measures were significant bacteriuria in a midstream clean catch urine sample collected 24 hours postoperatively, urinary symptoms like dysuria, urinary frequency and urgency, urinary catheterization necessitating re-catheterization. Other outcome measures were the time till start of oral re-hydration and return of intestinal sounds after the operation, the time of first voiding, post-operative ambulation time and the length of hospital stay. The results of the above-mentioned study are comparable to our observation in relation to all parameters.

In our observational randomized control trial, where immediate removal of indwelling catheter after caesarean section was compared with the conventional practice of removing catheter after twelve hours of operation. Both the study and the control groups were well matched in terms of maternal age, Body Mass Index, socio-economic status, gestational age in weeks, and incidence of previous Caesarean section. In our study, the incidence of catheter related significant bacteriuria is statistically significant in the control group which is comparable to the study conducted by Thomas M. Hooton et al. ${ }^{10}$ In a study conducted by Maki DG et al. the incidence of frank symptoms like dysuria, urgency, frequency is directly proportional to duration of indwelling catheter, with cumulative increase of $3-6 \%$ of the risk of bacteriuria at 24 hours with catheter-in-situ ${ }^{11}$ which is comparable to our study. However, the incidence of fever between the two groups shows no significant difference, probably due to use of proper antibiotics with the appearance of other symptoms.

Some studies show that there is gradual increased incidence of infections with each day of indwelling catheterization. ${ }^{12}$ In a study by Onlie et al. ${ }^{13}$ incidence of positive urine cultures 72 hours post-operatively for women in the immediate catheter removal group was lower compared with those who were catheterized for 24 hours. Both of these observations are comparable to our present study.

In the Philippine study conducted by Arlyne E. Naguimbing-Cuaresma and Antonia E. Habana ${ }^{14}$ it is also found that early removal of urinary catheter after a caesarean section offers more advantages to the patient in terms of shorter hospital stay and earlier ambulation time. Our study also corroborates this observation. Urinary Tract Infection, however, not assessed in their study.

Some studies suggest that the advantages of early removal of catheter may be outweighed by increased risk of re-catheterization with all of its associated complications. But, in our study, re-catheterization rate in immediate catheter-removal group and the group with removal of catheter after 12 hours were similar [Table 3] and not statistically significant $(\mathrm{p}=0.73620)$.

\section{CONCLUSIONS}

Prolonged catheterization after Caesarean section is associated with higher incidence of urinary complications along with problems associated with delayed ambulation and longer hospital stay. Immediate removal of the catheter after caesarean section seems to be more advantageous. Moreover, immediate removal of catheter was not associated with any adverse outcome. There was no increased risk of recatheterization. But in this study, patient's satisfaction, another advantage of immediate removal of catheter was not measured. Also, wound infection and intercurrent infections which may alter ambulation and hospital stay etc., were not considered separately which may minimally alter the data. It is hoped that the results of the study will be clinically useful, and it will be beneficial in formulating a strategy of removal of catheter after caesarean section. However, to formulate a globally accepted protocol regarding time of catheter removal, studies with larger sample size and preferably multi-centric studies are necessary.

\section{ACKNOWLEDGEMENT}

We would like to thank our patients for their kind cooperation in participating in our study. We would like to thank the post-graduate trainees of our unit of this hospitalDr. Avijit Pan, Dr. Antara Priyadarshini, Dr. Archi Ghanti, Dr. Nirupoma Dey and Dr. Pinky Biswas.

\section{REFERENCES}

[1] Pahari K, Ghosh A. Study of pregnancy outcome over a period of five years in a postgraduate institute of west Bengal. J Indian Med Association 1997;95(6):172-4.

[2] Sreevidya S, Sathiyasekaran BW. High caesarean rates in Madras (India): a population-based cross sectional study. BJOG: an International Journal of Obstetrics and Gynaecology 2003;110(2):106-11.

[3] Silver RM, Landon MB, Rouse DJ, et al. Maternal morbidity associated with multiple repeat caesarean deliveries. Obstet Gynecol 2006;107(6):1226-32.

[4] Arulkumaran S, Cheng S, Ingemarsson I, et al. Is there a need for routine indwelling catheter after caesarean section? Singapore Med J 1986;27(1):54-7.

[5] Cunningham FG, MacDonald PC, Gant NF. Williams Obstetrics. 22 $2^{\text {nd }}$ edn. New York: McGraw-Hill Publication 2005.

[6] Saint S, Wiese J, Amory JK, et al. Are physicians aware of which of their patients have indwelling urinary catheters? Am J Med 2000;109(6):476-80.

[7] Schwartz MA, Wang CC, Eckert LO, et al. Risk factors for urinary tract infection in the postpartum period. Am J Obstet Gynecol 1999;181(3):547-53.

[8] El-Mazny A, El-Sharkawy M, Hassan A. A prospective randomized clinical trial comparing immediate versus delayed removal of urinary catheter following elective cesarean section. Eur J Obstet Gynecol Reprod Biol 2014;181:111-4.

[9] Lumbiganon P, Laopaiboon M, Gulmezoglu AM, et al. Method of delivery and pregnancy outcomes in Asia: the WHO global survey on maternal and perinatal health 2007-08. Lancet 2010;375(9713):490-9. 
[10] Hooton TM, Bradley SF, Cardenas DD, et al. Diagnosis, prevention and treatment of catheter associated urinary tract infection in adults: 2009 International Clinical Practice Guidelines from the Infectious Diseases Society of America. Clinical Infectious Diseases 2010;50(5):62563.

[11] Maki DG, Tambyah PA. Engineering out the risk for infection with urinary catheters. Emerg Infect Dis 2001;7(2):342-7.
[12] World Health Organization. World Health Statistics 2009. [www.who.int/whosis/whostat/2009/en/index.html]. Last accessed 11 May, 2010.

[13] Onlie TG, Kuti O, Orji EO, et al. A prospective randomized clinical trial of urethral catheter removal following elective caesarean delivery. Int J Gynaecol Obstet 2008;102(3):267-70.

[14] Arlyn E, Naguimbing-Cuaresma, Habana MAE. Early removal of urinary catheter in caesarean delivery in a tertiary training hospital. Philippine Journal of Obstetrics $\&$ Gynaecology 